\title{
Urdimento
}

Revista de Estudos em Artes Cênicas E-ISSN: 2358.6958

\section{Performance do Encontro: Práticas performativas em tempos de presença real e virtual}

Renata Teixeira Ferreira da Silva

Suzane Weber da Silva

\section{Para citar este artigo:}

SILVA, Renata Teixeira Ferreira da; SILVA, Suzane Weber da. Performance do Encontro: Práticas performativas em tempos de presença real e virtual. Urdimento, Florianópolis, v. 3, n. 39, nov./dez. 2020.

DOI: http:/dx.doi.org/10.5965/14145731033920200212

Este artigo passou pelo Plagiarism Detection Software | iThenticate 


\title{
Performance do Encontro: práticas performativas em tempos de presença real e virtual
}

\author{
Renata Teixeira Ferreira da Silva \\ Suzane Weber da Silva²
}

\begin{abstract}
Resumo
Este artigo teve como objetivo apresentar procedimentos da prática performativa que evidenciam o encontro em tempo real no cotidiano urbano, advindo da Pesquisa Performance do Encontro. Para tanto, foram exploradas as noções de re-enactment e de acaso, explicitadas em narrativas de experiências próprias na criação de programas performativos, e também a partir de reflexões acerca da prática de duas performers, Eleonora Fabião e Tania Alice. As camadas espectatoriais da Performance do Encontro foram aqui examinadas considerando o momento de isolamento social vivenciado frente a COVID-19.
\end{abstract}

Palavras-chave: Encontro. Presença. Performance. Desdobramentos. Isolamento Social.

\section{Encounter Performance: performatives practices in times of real and virtual presence}

\begin{abstract}
This article aimed to present procedures of the performative practice that evidence the meeting in real time in the urban daily life, coming from the Research of Encounter Performance. For that, the notions of re-enactment and chance were explored, made explicit in narratives of own experiences in the creation of performative programs, and also, from reflections about the practice of two performers: Eleonora Fabião and Tania Alice. The spectator layers of the Encounter Performance were verified and analyzed taking into consideration the moment of social isolation experienced in face of COVID-19.
\end{abstract}

Keywords: Encounter. Presence. Performance. Developments. Social Isolation.

\footnotetext{
${ }^{1}$ Mestra em Artes Cênicas pela Universidade Federal do Rio Grande do Sul (2016) e Licenciada em Teatro pela mesma Universidade (2012). Ministra aulas de teatro e dança desde 2010 em diversas escolas da rede privada de ensino da cidade de Porto Alegre. renata.teixeira@globo.com

2 Bolsista Capes-Print para realização de Pós-Doutorado na Coventry University/Centre for Dance Research (Reino Unido) em 2019/20. Doutora em Estudos e Práticas das Artes pela Université du Quebéc à Montréal (UQAM/Canadá/2010). Professora do Departamento de Teatro e atua também como professora integrante do Programa de Pós-Graduação em Artes Cênicas da Universidade Federal do Rio Grande do Sul (PPGAC/UFRGS). ssuzaneweber@gmail.com
} 
Performance del Encuentro: prácticas performaticas en tempos de presencia real y virtual

\section{Resumen}

Este artículo tuvo como objetivo presentar procedimientos de la práctica performativa que evidencian el encuentro en tiempo real en el cotidiano urbano, proveniente de la Investigación Performance del Encuentro. Para esto, se exploraron las nociones de re-enactment y del acaso, explícitas en narrativas de experiencias propias en la creación de programas performativos, y también, a partir de las reflexiones sobre la práctica de dos performers, Eleonora Fabião y Tania Alice. Las capas espectadoras de la Performance del Encuentro fueron examinadas considerando el momento de aislamiento social vivido frente al COVID-19.

Palabras clave: Encuentro. Presencia. Performance. Desarrollos. Aislamiento social. 


\section{Desenredar}

Neste momento, em que vivemos um período de Pandemia Mundial, com o Corona vírus, em que as relações e individualidades estão fragilizadas em diversas dicotomias, tais como: isolada versus protegida, confinada versus salvando vidas, fim do mundo versus início de um novo mundo, tragédia versus mudança, problemas versus oportunidades, medo versus confiança, solidão versus autoconhecimento, tédio versus pausa para a criatividade, trazemos esse estudo, da Performance do Encontro, como forma de unir a nostalgia de quando podíamos conviver em sociedade e a resiliência de que tudo isso vai passar e vamos nos reencontrar em breve.

Durante a pesquisa de mestrado Performance do Encontro: um estudo de práticas performativas ${ }^{3}$, realizada nos anos de 2014 a 2016, nas cidades de Porto Alegre e Rio de Janeiro, estávamos em busca de uma prática que propiciasse uma experiência de aproximação com o outro, do encontro em tempo real. A cena política e artística estava efervescente no país, com diversos movimentos que eclodiram nas passeatas de junho de 2013, no Brasil inteiro, e que, seguiram ganhando força e espaço, tendo a rua como cenário e meio de visibilidade. Assim, tornou-se emergente nesse percurso, o desejo de ir para o meio urbano para conversar e compartilhar experiências com pessoas desconhecidas, transeuntes da cidade de Porto Alegre. No entanto, tinha-se a necessidade de realizar esse convívio através de um viés artístico, de criação, de partilha e não somente por meio de entrevistas, conforme já havíamos proposto em outros estudos. De modo geral, as entrevistas em sua forma tradicional, trazem um caráter formal à conversa, o que iria na contramão desta proposta de reinventar, conforme trazida pela pesquisadora cubana Ileana Diegues Caballero (2011, p. 23):

Numa sociedade de discursos esgotados, onde a população civil tem explorado recursos de representacionismo, e tem usado o seu próprio corpo como meio de expressão num entorno que midiatiza todas as

${ }^{3}$ A pesquisa de mestrado Performance do Encontro: um estudo de práticas performativas, orientada pela professora Dra. Suzane Weber da Silva, foi realizada com apoio da Coordenação de Aperfeiçoamento de Pessoal de Nível Superior - Brasil (CAPES) - Código de Financiamento 001. 
intervenções, a teatralidade, como a vida, tem que reinventar-se a cada dia, assumindo o mesmo risco, a mesma fragilidade e sobrevivência que marca os espaços onde se insere.

Desta forma, nos aproximamos através de textos, da performance feita pela artista Eleonora Fabião, denominada Ações Cariocas 1(2008), criação que faz parte de sete ações intituladas Ações Cariocas, realizadas por Fabião. Nesta proposta, a performer vai para o centro da cidade do Rio de Janeiro com dois banquinhos, retirados da casa dela, e propõe conversar sobre qualquer assunto com os transeuntes através de um cartaz. Consequentemente, a pesquisa Performace do Encontro: um estudo de práticas performativas (Silva, 2016) foi inspirada pela maneira que a artista escolheu para discutir assuntos emergentes da cidade, pois durante os dias em que Eleonora realizou a performance, ela exibiu cartazes com as diferentes frases: "Converso sobre qualquer assunto", "Converso sobre política”, "Converso sobre amor" e "Converso sobre saudade", em uma proposta de conversar com o estranho, colocando-se em relação direta com os transeuntes, corpo frente a corpo. Despertando para a performance que foi concebida como Converso sobre teatro (Silva, 2013).

Este diálogo estabelecido no meio urbano por Eleonora, sem uma espetacularidade associada a uma dimensão de grandiosidade ou virtuosidade, mas ao contrário, aliado a uma valorização do simples, do comum, do ordinário, motivou uma diferente forma de conversar, de trocar, de partilhar uma ação. Desta maneira, a partir da experiência do corpo em performance na rua, da vivência em re-atualizar a obra de Fabião, o interesse convergiu para a investigação de práticas artísticas e performances que evidenciam ações banais, cotidianas, ordinárias e de fácil acesso a todos. Associamos criações que transitam em uma linha tênue entre arte e vida, e que destacam em suas propostas o aspecto relacional da arte (Bourriaud, 2009), colocando em evidência também a mulher comum e enfatizando a arte enquanto processo.

Interessou a esta pesquisa, o performer que assume o papel de "ritualizador do instante-presente" (Cohen, 2002, p. 91), destacando o trivial do dia-a-dia e desta forma, valorizando-o, em um processo de reflexão e ressignificação do gesto, do 
tempo e do espaço. Assim, a busca está em estabelecer um momento de troca com o outro, de "interação social real" (Bauman, 2001, p. 124), que propõe uma vivência compartilhada (e não somente a ocupação de um espaço físico concomitantemente), que desarticula hábitos cristalizados da modernidade, como realizar tarefas cotidianas de maneira automática ou estabelecer conversas que não passam de roteiros pré-estabelecidos, sem escuta ou interesse. Ao disponibilizar um banco em meio ao centro do Rio de Janeiro, Fabião interrompe um fluxo maquinal de idas e vindas a fim de produzir presença, troca e ação consciente.

Do mesmo modo, também estabelecemos proximidade da performance Converso sobre teatro (Silva, 2013) com outra criação, como a performance Ulysses - Live Art after breakup (2014), da performer Tania Alice. Esta performance tem como ação rir com os participantes durante horas, enquanto são projetados vídeos de ações de uma série de performances feitas anteriormente. Essas imagens projetadas são registros de performances realizadas por intermédio de uma rede social, em que os internautas propunham atividades a serem realizadas por Tania Alice, a fim de motivar a artista após o fim de um relacionamento amoroso. Em ULySseS - Live Art after breakup (2014), artista e espectadorcolaborador sentam-se um de frente para o outro, abertamente, borrando, misturando e fundindo as barreiras que segregam performer e espectador, na busca de uma linha horizontal de criação, de colaboração, a partir da ação simples e cotidiana de rir. Assim, ao propor a ação de rir com o outro como poética em sua performance, a artista fricciona arte, ação ordinária e meditação, produzindo uma forma insurgente de ser e estar e atendendo a uma necessidade social, apontada pelo sociólogo Boaventura de Souza Santos:

[...] não é simplesmente de um conhecimento novo que necessitamos; o que necessitamos é de um novo modo de produção de conhecimento. Não necessitamos de alternativas, necessitamos é de um pensamento alternativo às alternativas. (Santos, 2007, p.20).

É possível perceber semelhanças entre os trabalhos, afinal as ações compreendem sentar-se frente a frente, constituindo essa relação frontal dos 
corpos e deste modo, favorecendo a relação não hierárquica da performance (Cohen, 2002). Há pela artista uma busca de atenuar a distinção de quem atua e quem recebe através do espaço e da proposta de performer e espectador colaborarem na realização de uma ação. O procedimento de sentar como uma oportunidade do corpo encontrar certo relaxamento e conforto, propiciando um deslocamento da atenção à organização gravitacional (Godard, 2001) do indivíduo, para a escuta. O olhar à frente estabelece um processo de abertura de si ao encontro do outro e de reelaboração desses corpos, pois "Através desses encontros estranhos, ambos os corpos são de-formados e re-formados, eles tomam forma através de outras formas corporais”" (Ahmed, 2000, p. 39). É no espelho do outro, que acontece a percepção de tudo que está e não está contido em nós e o que fica após a despedida já está alterado (de-formado e re-formado), um corpo "assinado por muitos outros.” (Certeau, 2014, p.159).

A estratégia de fazer de novo, de voltar a citar uma performance já conhecida, faz parte de um procedimento que os performers vêm utilizando de modo frequente. Nesta pesquisa trata-se também de desdobrar, de reatualizar, de reencenar, de rerritualizar práticas de performance que vêm sendo realizadas nos últimos anos.

Deste modo, ao pensar nesses desdobramentos da prática de Fabião e Alice, na performance realizada na rua, nas ruas da cidade de Porto Alegre ${ }^{5}$, e no artista que dialoga com os transeuntes, pensamos no aspecto urbano incorporado enquanto temática da performance. O performer que entende a cidade não como um cenário ou pano de fundo, mas como um espaço ativo, propositivo, capaz de movimentar a cena. É na interferência da performer sobre o espaço que se pode fazer parar o transeunte, aí se encontra a brecha da ruptura, embora, a cidade não pause. A ação da performer busca quebrar com a constante passagem dos

\footnotetext{
4 Through such strange encounters, bodies are both de-formed and re-formed, they take form through and against other bodily forms. (Tradução nossa)

${ }^{5}$ Porto Alegre, capital do Rio Grande do Sul, é uma cidade que tem uma notória diversidade de espetáculos, shows e eventos. Pois, além das temporadas de grupos locais, a programação anual do município conta também com importantes festivais: Teatro de Rua, Palco Giratório-SESC-RS, Porto Alegre em Cena, entre outros. E é uma cidade importante nas manifestações populares, como nos protestos de 2013, em oposição ao aumento do preço do transporte público, e no ano de 2015, com as marchas feministas contra a aprovação do projeto de lei 5069/2013.
} 
transeuntes e desvelar um novo instante, possibilitando que novos olhares surjam e que ressignifiquem este espaço ordinário em uma nova proposta de relação para/com ele, conforme explicitado por André Carreira (2009, p. 3)

Neste sentido, é preciso considerar a ideia de invasão teatral não apenas desde uma perspectiva definida pela ação política ou por um compromisso radical, mas sobre tudo desde uma perspectiva que toma a cidade como um campo simbólico no qual o teatro se instala, inevitavelmente, como elemento de ruptura com os fluxos do cotidiano.

Com vistas a este panorama, acreditamos na utilização do espaço urbano na performance como um ato político. Acreditamos na performance que dialoga com assuntos urgentes da cidade em suas temáticas de emergência e na ausência de políticas públicas para as minorias. O espaço público como um lugar comum a todos, e por isso a possibilidade de todas as vozes terem escuta, espaço de acesso de todas as culturas e classes sociais, mesmo que se saiba que o sentimento de pertencimento aos espaços urbanos seja flutuante. Tais propostas que colocam as mais diferentes pessoas em estado de encontro possibilitam afeto ${ }^{7}$ (Brinkema, 2014) e mais proximidade entre os indivíduos, quebrando com alguns padrões de comportamento e de convivência que lidamos no cotidiano. Segundo a diretora teatral Patrícia Fagundes ${ }^{8}$ abrir-se para essa possibilidade do encontro é:

[...] estar aberto ao mistério do outro em um difícil exercício de humildade, despojamento e escuta que implica uma atitude ética e artística extremamente exigente e significativa, mesmo que possa parecer que se mova por territórios limitados. O mundo é feito de relações. (Fagundes, 2009, p. 39).

Assim, foi por esse mistério do outro, que o estudo em questão nesse artigo,

\footnotetext{
${ }^{6}$ André Luiz Antunes Netto Carreira é diretor de teatro brasileiro e professor da Universidade do Estado de Santa Catarina. Desenvolve pesquisas no âmbito de teatro de rua e performance. Destacamos aqui, seu último livro Teatro de invasão do espaço urbano: a cidade como dramaturgia (2019).

7 Para Eugenie Brinkema, o afeto é "o que desfaz, o que perturba, o que eu não posso nomear, o que resta (assombra, e sempre tão bonito), o que resiste; indefinível, diz-se ser o que não pode ser escrito, o que derrete a crítica fria, mexe em todos os sistemas”. (Brinkema, 2014, p. xxi). (Tradução nossa)

8 Patrícia Fagundes é diretora da Cia Rústica e professora de Direção Teatral no Departamento de Arte Dramática da UFRGS. (Disponível em: <http://ciarustica.com/quem-somos/. Consultado em: 23 mar. 2015).
} 
Performance do Encontro, pretendeu percorrer, abrindo-se para o próximo, dialogando e usufruindo da cidade enquanto um espaço facilitador de encontros, "um assentamento humano onde estranhos têm a chance de se encontrar" (Bauman apud Sennet, 2001, p. 121). Consequentemente, descobrindo mais do que procedimentos, mas modos de ser e estar, enxergando outras formas de fazer arte, reelaborando, reinventando, recriando e transformando dentro e fora de si.

\section{Costurar}

A constituição desse corpus de estudo ultrapassa os limites de interesse de uma poética a fim de se constituir também enquanto resistência e representatividade. Trata-se da força das mulheres em cena, seja performando, dançando, atuando, criando arte ou produzindo conhecimento e reflexão especializados através de sua prática. Na história da performance, contamos com nomes importantes de transformação dos paradigmas do papel da mulher branca na sociedade, seus limites e espaços, e assim, transgredindo as regras e limites de ação do corpo feminino para além do privado. Destaco o caráter de mulheres brancas, pois trago uma lista de performers brancas e sabemos que, conforme a filósofa Djamila Ribeiro, o discurso universal é excludente:

[...] as mulheres são oprimidas de modos diferentes, tornando necessário discutir gênero com recorte de classe e raça, levando em conta as especificidades de cada uma. A universalização da categoria "mulheres" foi feita tendo como base a mulher branca de classe média - trabalhar fora sem a autorização do marido, por exemplo, jamais foi uma reivindicação das mulheres negras ou pobres. (Ribeiro, 2018, p.45-46).

Entre a década de 1960 e 1970 houve diferentes manifestações de artistas na área da dança, performance, teatro e música, e com os movimentos da Judson Dance e do Fluxos, podendo citar os nomes das artistas Trisha Brown, Yvonne Rainer, Carolee Schneemann, Alison Knowles, Yoko Ono, Lucinda Childs, Anne Halprin, entre outros. A nova iorquina Trisha Brown, por exemplo, chocou a todos com o experimento Man walking down the side of the building (1970), em que um 
performer caminhou suspenso por corda em um edifício de sete andares, em Nova York. Essa performance, invertendo a gravidade sob o qual o corpo é submetido tradicionalmente na verticalidade (em pé) e submetendo o corpo na horizontalidade, explicita o quanto a ação de caminhar é construída diariamente num jogo com a gravidade. Esse jogo corporal é quase imperceptível porque é onipresente na ação humana de ficar em pé no dia a dia. (Goldberg, 2006).

Em Paris, Gina Pane ${ }^{9}$ com seus cortes auto-infligidos, apresentou o corpo como seu material artístico. Na performance O condicionamento (1972) "apresentava Pane deitada numa cama de ferro com algumas barras transversais, por baixo, quinze longas velas acesas” (Goldberg, 2006, p. 155), instigando a reflexão acerca da suposta fragilidade do corpo da mulher. Ainda na Europa, Marina Abramovich apresentou diversos trabalhos que testavam os limites corporais e os limites do desejo dos espectadores, colocando em uma das suas performances, Ritmo O (1974), um revólver carregado à disposição do público. (Goldberg, 2006).

Estas mulheres, em diferentes gerações, com modos diversos, têm em comum a vontade de tornar o pessoal, público (Oliveira, Pinho, 2012), de romper as fronteiras impostas a elas pelo simples fato de serem mulheres. Desta forma, essas artistas em seus trabalhos propõem ações que questionam a dualidade feminino versus masculino, desestabilizando certezas e ocasionando transformações em suas gerações.

Eleonora Fabião e Tania Alice são exemplos atuais que se destacam no meio artístico no que se refere a performance ${ }^{10}$. Além disso, elas foram inspiração para a pesquisa citada porque são mulheres, porque são mães e assim enfrentam, como nós, os desafios de se fazer performance na contemporaneidade, onde ainda o nosso corpo é motivo de medo, de desrespeito e de sonegação. O corpo

\footnotetext{
9 "Gina Pane (1939-1990) foi uma artista francesa de origem italiana que trabalhava a instalação e a performance. Gina Pane é mais conhecida como umas das poucas artistas do gênero feminino da década de 1970 que usou o corpo em seu trabalho de maneira extrema, incluindo lesões auto-infligidas. Seu uso do corpo como ferramenta artística revela vulnerabilidade tanto em um sentido real e literal."

(Disponível em: <http//www.veniceperformanceart.org/índex.php?page=223\&Lang=em>. Acesso em: 28 jan. 2016).

${ }^{10}$ Alice (2017a, 2017b, 2017c, 2014 e 2011a, 2011b) e Fabião (2013, 2010, 2009, 2008, 2006) têm escrito nos últimos anos inúmeros artigos sobre performance.
} 
feminino está sujeito fortemente à desvalorização se não atende aos padrões da macro-sociedade, tais como os divulgados nas publicidades e novelas, comumente mulheres altas, magras, brancas e jovens. Ou seja, a mulher até pode ser valorizada na sociedade, contanto que ela atenda a uma determinada expectativa da grande mídia, resumido pela jornalista Alexandra Gurgel (2018, p. 36):

Resumindo, a mulher estuda mais, ganha menos, trabalha mais, sofre violência de inúmeras formas, é sempre subjugada e questionada e ainda tem que apresentar uma fachada comercial (ser bonita, magra, maquiada, alinhada). Isso porque nem falamos de corte de sexualidade (as lésbicas têm menos oportunidades), raça (as brancas ganham mais do que as negras), regionalismo (as nordestinas são as que mais sofrem com essa disparidade salarial), classe (mulheres da periferia têm menos oportunidades de trabalho) e corpo (mulheres gordas têm menos espaço no mercado de trabalho).

As mulheres negras ainda estão em maior desvantagem, pois segundo estudo realizado pelo PNAD (Pesquisa Nacional por Amostra em Domicílios), e debatido em evento em comemoração ao dia da mulher em março de 2019, pelo IPEA (Instituto de Pesquisa Econômica Aplicada), as mulheres brasileiras ganham, em média, $76 \%$ da remuneração masculina e as mulheres negras recebem ainda menos, 43\% dos salários dos homens brancos. E para as profissionais do mainstrean não é diferente, a exemplo de Viola Davis ${ }^{11}$, que fez um discurso ao ser a primeira mulher negra a ganhar o prêmio Emmy na categoria de melhor atriz de drama e evidenciou em sua fala, que: "a única coisa que separa mulheres negras de qualquer outra pessoa, é a oportunidade".

Para este artigo é importante salientar o caráter contraventor e provocador de Tania Alice e Eleonora Fabião, duas performers que residem no Rio de Janeiro e que realizam suas performances em todo o Brasil e têm forte visibilidade no exterior, atuando nas ruas, em galerias e lugares inusitados, colocando-se em evidência e assim, também em risco. Exemplos: Eleonora, em uma de suas performances, faz uma longa trajetória caminhando pelas ruas vestida de sacos

${ }^{11}$ Viola Davis ao ganhar o prêmio Emmy em 2015 realizou um discurso fervoroso reivindicando mais papéis de destaque em filmes para mulheres negras. (Disponivel em: <https://www.youtube.com/watch?v=e0M6Zn2UDQA .Acesso em: 28 jan. 2016). 
plásticos pretos, assemelhando-se a certos moradores de rua, ou no caso de Tania, que vestida de heroína buscou evidenciar os verdadeiros heróis do cotidiano. Estas artistas, de modo algum, reforçam o papel tradicional de conduta da mulher branca, classe média, idealizado pela sociedade em geral.

Mesmo que, suas práticas performáticas não sejam associadas à performance feminista de forma explícita, propondo outros eixos como o Precário (Fabião) ou a Performance Relacional de Cura (Alice), elas estão inseridas em um movimento de resiliência da mulher:

Na perspectiva da teoria feminista pós-moderna, a performance artística feita por mulheres apresenta-se como inerentemente política (quer o seja abertamente ou não), pois todas estas performances derivam da relação das mulheres com o sistema dominante de repressão, o que as situa dentro de uma crítica feminista. Por conseguinte, é inevitável o seu potencial disruptivo, já que estas mulheres posicionam-se aqui como sujeitos do discurso, subvertendo a conceptualização tradicional de um sujeito homem, único e unificado. (Oliveira, Pinho, 2012, p. 64).

Quando nos apropriamos da rua e tomamos nosso lugar - lugar de fala (Ribeiro, 2019) - nós assumimos o papel de protagonistas na articulação de ideias e saberes, e de propositoras de debate; e neste hiato conquistado, desmantelamos e reconfiguramos esse espaço, ocupado por primazia pelos homens brancos. E nesse movimento desbravador, passo a passo avançamos a uma zona de legitimidade, ainda não pertencente às minorias, assim como questiona Ribeiro:

Numa sociedade suprematista branca e patriarcal, mulheres brancas, mulheres negras, homens negros, pessoas transexuais, lésbicas, gays podem falar do mesmo modo que homens brancos cis heterossexuais? Existe o mesmo espaço e legitimidade? (Ribeiro, 2019, p.77).

Acreditamos que, refletir sobre a arte a partir de um prisma feminista é conceber a partir do ponto de vista das mulheres e de seus discursos, ações e práticas contestatórias em direção à opressão por elas sofridas no meio social. Reconhecer a importância desse ponto de vista é algo recente, pois ainda é emergente a nova historiografia sob a influência do feminismo. Há somente algumas décadas que se evidenciou o quanto a dominação masculina, em quase 
todos os setores da sociedade, impõe às mulheres a invisibilidade, o silêncio e busca pelo confinamento ao privado. Por isso, a história das mulheres é, antes de tudo, a história dos corpos das mulheres.

\section{Experimentar}

A pesquisa foi composta também por experimentos práticos performáticos na busca por compreender, relacionar e explorar algumas reflexões teóricas realizadas durante o processo, mas também a fim de criar, de vivenciar e de friccionar desejos e inquietações que surgiram ao longo da pesquisa.

Os experimentos performáticos são algumas práticas próprias em performance, a partir da construção de programas, que segundo Fabião (2008) são a organização do planejamento da performance a ser realizada. As ações foram realizadas entre os meses de maio de 2013 e janeiro de 2015. Neste recorte, são descritas e analisadas três experiências em performance na rua, que interagem com os transeuntes. Foram organizadas em dois momentos, pois o experimento de número dois é um desdobramento do número um, que parte de um mesmo substrato, procedimento, e o de número três se diferenciando conceitualmente dos demais.

Tendo em vista o novo panorama, do Teatro Pós-Dramático, em que a arte não tenta propor uma "representação, mas uma experiência do real (tempo, espaço, corpo)" (Lehmann, 2007, p. 223) ou segundo Féral, da noção de Teatro Performativo em que se instaura uma "estética da presença” (Féral, 2008, p. 209), os experimentos performáticos realizados durante essa pesquisa investem na tentativa de relação não hierarquizada entre performer e espectador, que é um dos desafios encontrados ainda hoje, como corrobora a citação abaixo:

Acredito que reside aí uma dimensão política das artes cênicas, onde diferentes possibilidades de colaboração e de improvisação concebem novas formas de participação, percepção, liberdade e sociabilidade. Um dos desafios da contemporaneidade nas artes cênicas ainda é oferecer ao espectador tradicionalmente passivo novas maneiras de trocar, de interagir, de dialogar e de colaborar. (Weber, 2010, p. 48). 
À procura por entender a relação do espectador e do performer, em um contexto de práticas que têm como objetivo estabelecer maneiras mais criativas, afetuosas e cooperativas de se relacionar, investigamos as nuances de colaboração do espectador. Para isso, partimos da noção de emancipação do espectador desenvolvida pelo filósofo francês Jacques Rancière (2010, p. 113) em que: "Emancipação é o processo de verificação da igualdade de inteligência”, para analisar e caracterizar o papel do espectador e suas possíveis camadas na performance realizada na rua.

Desta forma, utilizamos registros fotográficos da performance Converso sobre teatro 2 (Silva, 2014), segundo experimento performático realizado na pesquisa, em que pudemos verificar diferentes formas de interação do espectador com a ação e com a artista. Assim, organizamos camadas de contato a partir das imagens selecionadas, importando à análise o grau de envolvimento, de troca e ação estabelecida entre os participantes.

A primeira camada se refere ao sujeito que por ali passa e modifica minimamente a sua trajetória, ralenta um pouco a caminhada, espia e rapidamente procura compreender o que ocorre de modo superficial, é o espectador transeunte. Ele proporciona movimento à cena, pois sua caminhada é contínua e ajuda a constituir junto com os elementos o espaço da performance. Desta forma, algo se altera, aquele espaço de asfalto ganha outra função, a cena traz curiosidade aos passantes, a caminhada ganha propósito naquele instante e os fragmentos de história, explicitados pelo pensador francês Michel de Certeau, modificam-se:

As redes dessas escrituras avançando e entrecruzando-se compõe uma história múltipla, sem autor nem espectador, formada em fragmentos de trajetórias e em alterações de espaços: com relação às representações, ela permanece cotidianamente, indefinidamente, outra. (Certeau, 1994, p. 159). 
Figura 1 - Espectador transeunte.

Converso sobre teatro 2, 2014. Foto: Matheus Soares

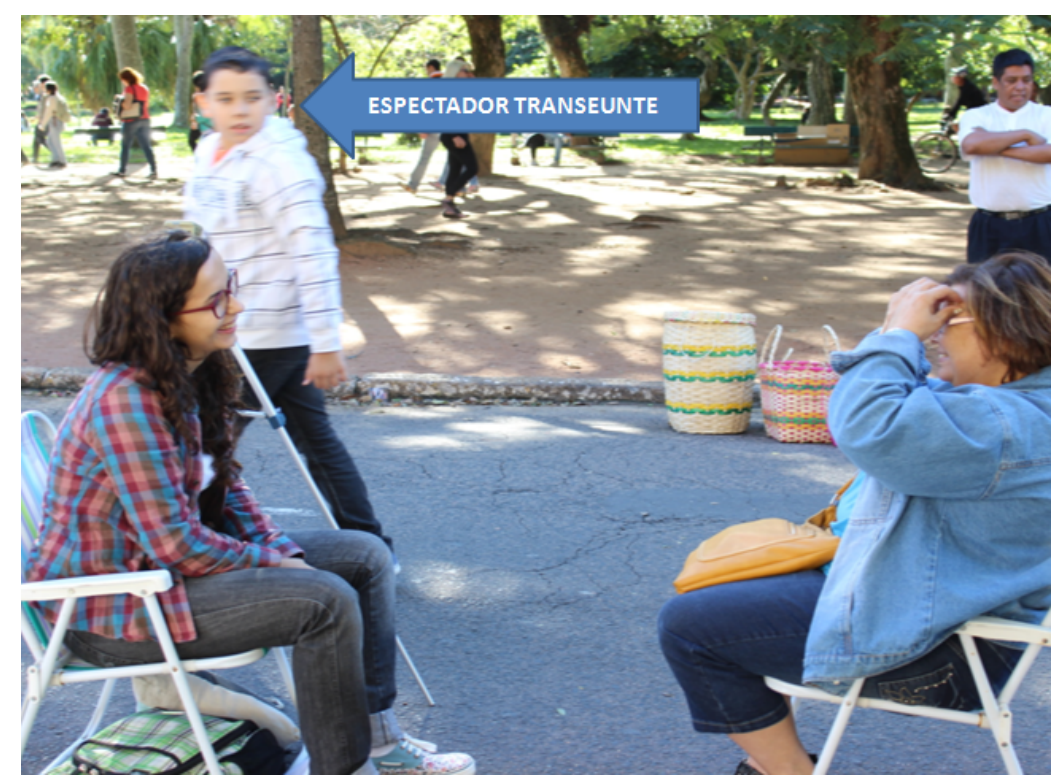

Já o espectador observador integra uma segunda camada, porque ele suspende a caminhada e desta forma vê o acontecimento amplamente, acompanha a proposta da performer e percebe a tomada de posição (Fabião, 2008) do espectador-colaborador ao aceitar o convite à experiência. Todavia, ele ainda está distante, não se coloca em risco e sua principal ação, assim como a do espectador transeunte, é olhar, com a diferença que o espectador observa a continuidade e desenvolvimento da ação. Ambos os espectadores (transeunte e observador) já estão em uma condição de emancipação, já que o olhar/ver são formas ativas do espectador se colocar na cena, segundo Rancière (2010, p. 115): "Ela começa quando nos damos conta de que olhar também é uma ação que confirma ou modifica tal distribuição, e que ‘interpretar o mundo’ já é uma forma de transformá-lo, de reconfigurá-lo." 
Figura 2 - Espectador observador.

Converso sobre teatro 2, 2014. Foto: Matheus Soares

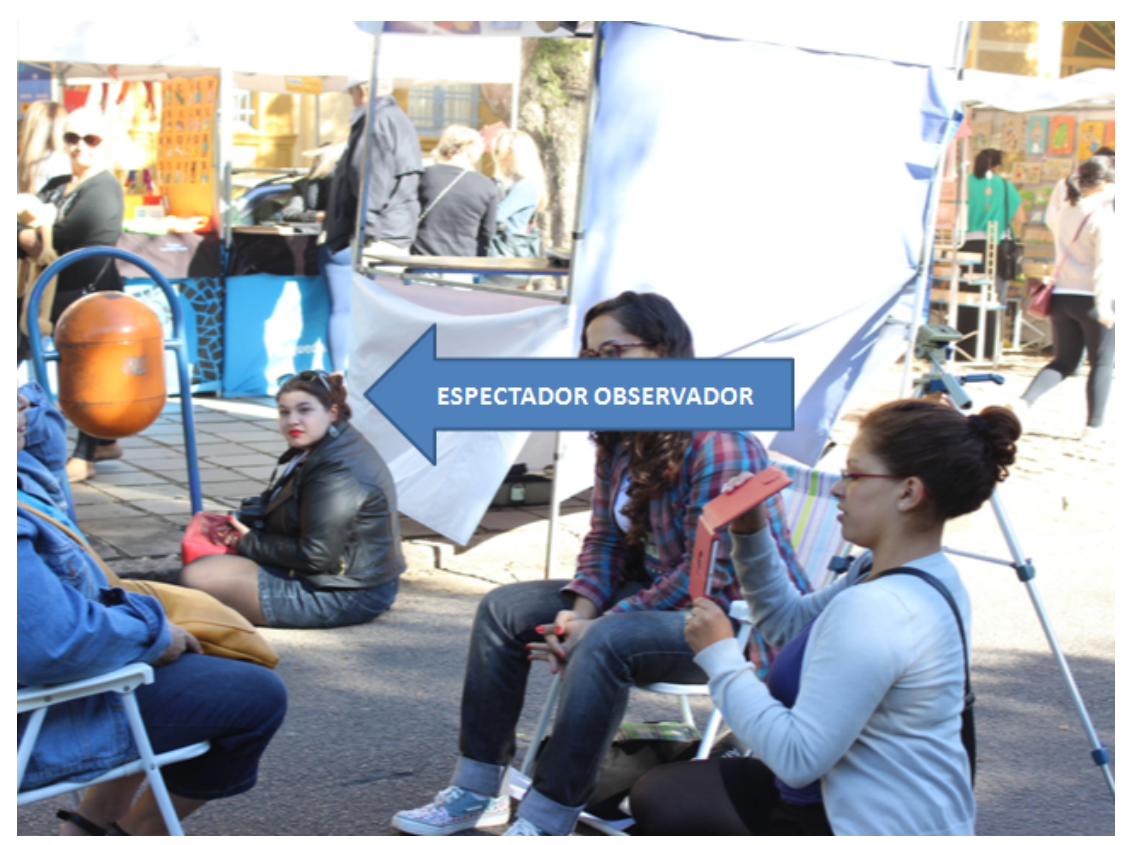

Desta forma, a terceira camada é chamada de espectador-colaborador, pois ele intervém na performance e compõe a cena no instante presente em parceria com o artista, se coloca em risco e se insere na obra, dissolvendo a barreira que separa artista e espectador. Porém, para Ranciére (2010), colocar-se em situação de colaboração não torna o espectador mais ativo, mas sim torna o espectador parte constituinte da performance, indispensável naquele ato. Visto que. a condição de espectador já é ação, conforme o autor esclarece:

A condição de espectador não é uma passividade que deve ser transformada em atividade. É a nossa situação normal. Nós aprendemos e ensinamos, atuamos e sabemos, como espectadores que legam o que veem com o que já viram e relataram, fizeram e sonharam. Não existe meio privilegiado, assim como não existe um ponto de partida privilegiado. (Rancière, 2010, p. 118). 
Figura 3 - Espectador colaborador.

Converso sobre teatro 2, 2014. Foto: Matheus Soares

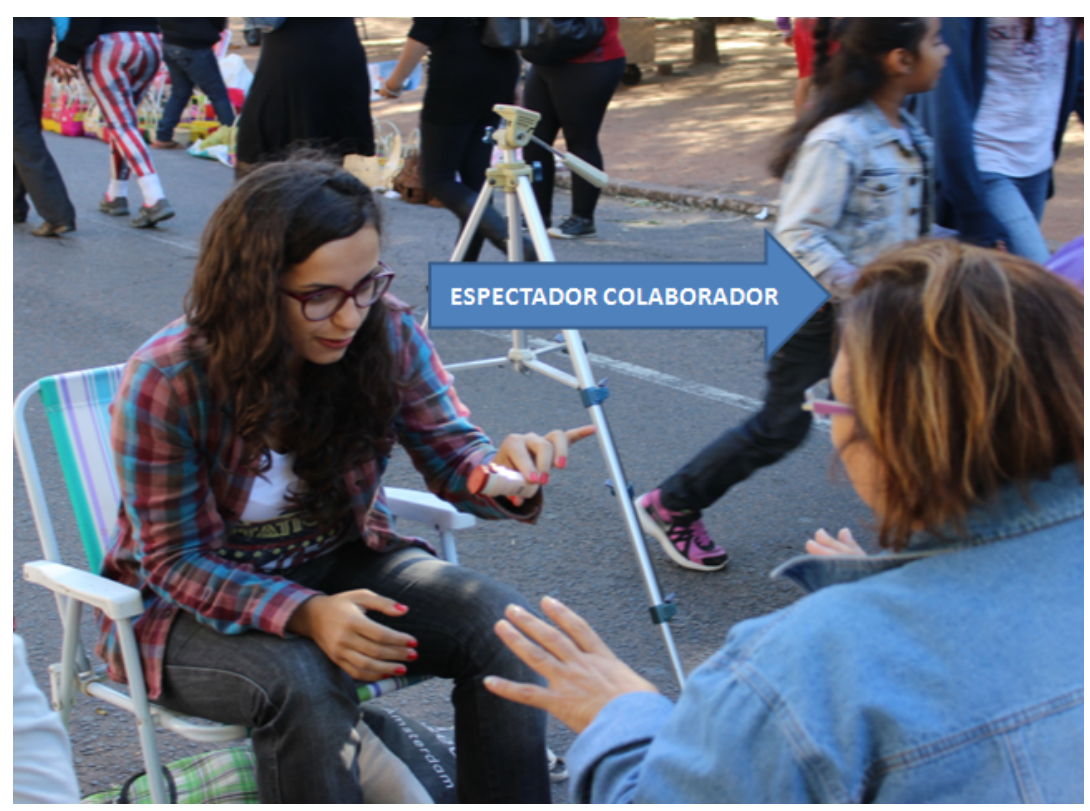

Sob esta ótica estabelecemos três níveis de aproximação e relação do espectador na performance, conforme ilustrada a seguir:

Figura 4 - Camadas espectatoriais na Performance do Encontro. Imagem: Renata Teixeira

\section{Espectador Transeunte}

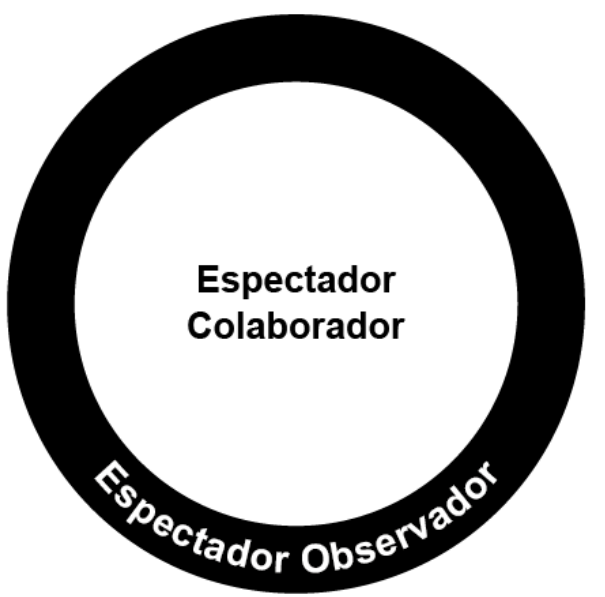


E o que seria a Performance do Encontro? O performer oportunizaria a partir do acontecimento performático o encontro do espectador-colaborador com o artista, o encontro de si e com a cidade em uma via direta, de mão dupla e de forma simples. O espaço urbano se transformaria, destacando-se efemeramente naquele instante da ação, recriando possibilidades espaciais e afetivas, características e funções e estabelecendo novas relações de ocupação para/com os transeuntes.

O encontro, o único lugar possível do teatro, uma ação coletiva, pode transformar, mesmo que momentaneamente, o estado dos sujeitos pósmodernos que transitam pelas ruas. Este sujeito pode ser submetido a transformações através de encontros proporcionados por ações artísticas, encontro de sujeito com outros ou consigo mesmo, em contato com as experiências de novas situações. (Bennaton, 2009, p. 37).

É nesse sentido que situamos este estudo e que estabelecemos a partir de procedimentos performáticos, seja como observadoras, observadoras-criadoras ou performers, buscando maneiras de ser e estar com o outro, propondo alternativas de colaboração com o espectador. Assim, percebemos que em propostas de Performance do Encontro o papel do espectador-colaborador é fundamental para sua concretização, uma vez que em relação, o diálogo se torna viável, potencializando transformações (do meio social e meio urbano) através desses corpos em estado de fricção.

\section{Procedimento 1 e 2: o re-fazer}

A escolha por repetir a performance Ações Cariocas 1 (2008) da artista Eleonora Fabião se apresentou nesse estudo como um importante procedimento de pesquisa em Performance. A partir da poética da artista, foi possível aprofundar questões conceituais, desestabilizar certezas, colocar-se em risco e assim, em estado de experimentação, descobrir procedimentos do performar. A influência estrutural da performance de Fabião, em que se constitui em duas cadeiras frente a frente e um cartaz invocando a colaboração dos transeuntes me aproximou de uma forma de fazer arte, que se estabelece de forma urbana, precária e política, 
que ao descolar-se da ideia de espetacularidade, evidencia, reflete, questiona e transforma o cotidiano e a arte, ou conforme a definição feita pela própria artista sobre seu trabalho: "precário, precário, precário" (Fabião, 2006). Percebeu-se nesse experimento de re-fazer, o meio urbano enquanto espaço/tempo, com seus diferentes ritmos, lugares de pertencimento, de encontros e desencontros, criando uma nova relação com a cidade.

Através do desdobramento de uma ação já realizada, o re-enactment aqui é compreendido como um estopim, um gatilho, uma potência. A partir de uma ação já realizada, o re-enactment se transfigura, assim como traduz Tania Alice (2011, p. 7):

Neste sentido, o re-enactment é um diálogo onde o corpo do performer que realiza o re-enactment tenta re-atar com a intensidade da proposta original, com um corpo ausente/presente, re-territorializando afeto e potências com as quais ele se identifica.

É nesse ato de re-fazer uma obra que podemos nos aproximar da noção de Oswald de Andrade, de um movimento antropofágico ${ }^{12}$, pois o re-enactment não significa cópia, representação gestual ou tradução de intenções, mas sim, um processo, que ao afirmar sua origem, transforma-se, reconstrói-se. Tal processo pode ser compreendido, assim como para Bellotto (2013, p. 102), enquanto um "palimpsesto", que a partir da criação, há a "autotransformação das referências", e desta forma, possibilita o descobrimento de outros procedimentos, caminhos, resultados e efeitos.

Colocar-se em ação, no ato do outro, na ação de Eleonora, caracterizou-se em pesquisa, aprendizado, reflexão e criação, pois mobilizando o que antes tinha sido compreendido teoricamente, na prática possibilitou que fosse incorporado, sentido e o que se receava anteriormente pode ser transmutado em estímulo. Para Ciane Fernandes, a prática corporal está justamente em destaque, e consideramos fundamental para esse estudo: "Na pesquisa em artes cênicas, o corpo é autor, criador e pesquisador; estudo, estudado e estudante; é o meio e o fim; tema e

12 O manifesto antropofágico de Oswald de Andrade em 1920 tratava de não negar a cultura exterior, norteamericana, mas sim degluti-la e atualizando-a com a cultura interior, brasileira. 
método; quem, o que, como e onde." (Fernandes, 2008, p.3).

Programa de Converso sobre teatro: Levar duas cadeiras para o Parque Farroupilha ${ }^{13}$ no domingo. Escolher o local com maior fluxo de transeuntes. Abrir as duas cadeiras uma de frente para a outra e sentar em uma delas. Escrever um cartaz com a seguinte frase: "Converso sobre teatro" e levantá-lo. Aguardar. Conversar. Despedir-me.

Porto Alegre, 26 de maio de 2013

Nesse primeiro experimento, buscamos principalmente perceber de que forma as relações entre temática e espectador se estabelecem, de como a proposição de conversar sobre teatro pode motivar, entretecer e favorecer um encontro entre estranhos.

O Parque Farroupitha proporciona esse tipo de encontro, pois é um espaço de lazer, arte e cultura, muito frequentado pela população e assim, assemelhandose ao Largo da Carioca de Fabião, que também tem ampla circulação de pessoas e comércio. Durante a performance, conversei com dois homens em momentos diferentes e que em certo momento descobrimos que eram pai e filho, mas não haviam se encontrado naquele dia ainda. Aqui podemos inferir um capital cultural4 (Bourdieu) adquirido e passado de uma geração para outra, em que ambos consideram importante as ações que pensam e repensam a cultura na cidade.

Cada encontro teve dimensão única, pois o caráter imprevisível a cada vez que a cadeira foi ocupada fomentou atenção e entrega. Estar disponível ao encontro e abarcar tudo que ele pode proporcionar foi uma tarefa de difícil realização, movimentando de maneira intensa os aspectos perceptivos. Desta forma, compreendemos ser mais importante aprofundar as questões de presença

\footnotetext{
13 O Parque Farroupilha, mais conhecido como Redenção, foi fundado em 19 de setembro de 1935 , administrado pela Secretaria Municipal do Meio Ambiente. Estima-se que mais de quatro milhões de pessoas passam por ano pela Redenção".

(Disponível em: <http://www.portoalegre.tur.br/ponto_turistico/parque_farroupilha_redencao-porto_alegre21-2-16-48.html>. Consultado em: 15 jun. 2014).

14 “Capital é aqui entendido não como o acúmulo de bens e riquezas econômicos, mas como algo específico que adquire um valor num determinado tempo e espaço, como saberes e conhecimentos que são reconhecidos em um determinado espaço social. (Weber, 2009, p. 4).
} 
e afeto, do que a busca por atingir o entendimento pleno do acontecimento. Sendo assim, neste experimento podemos destacar os aspectos de efemeridade e finitude do encontro com o estranho, evidenciando o instante conforme diz André Lepecki (2013, p. 117):

O que importa é o desejo de querer fazer pleno, mesmo que nunca se saiba de antemão o que virá a ser. Não se trata mesmo de construir algo sob espécie de alguma imagem do desejo que preexistiria e o amarraria. Trata-se de ousar fazer com o outro o fazer-se do encontro. Agarrar o evento e com ele entretecer o metaplano.

\section{Procedimento 3: o acaso}

Após algumas experiências práticas, em colaboração e preposição, e também através da compreensão de algumas noções e aspectos da Performance, foi necessária a busca por procedimentos performáticos que propiciassem explorar outras maneiras de ser e estar no mundo. Então, iniciamos um processo reflexivo acerca dos medos e barreiras criativas, dos limites impostos pela sociedade tradicional, procurando identificar os obstáculos que interferem na conexão do artista com o todo. Um dos pontos percebidos foi uma tendência em protagonizar o sentido da visão, e ao se ater ao sentido visual, a qualidade de vivenciar outras possibilidades sensoriais, diminui. Assim, para que pudéssemos ampliar, aprofundar e transformar as sensações e conexões com o espaço e com o outro, reconhecemos que deveríamos fechar os olhos e desse modo, buscar abertura para novas formas de se relacionar com o interior e o exterior. Para Tania Alice o desafio do performer está justamente em encontrar no autoconhecimento maneiras de agir:

Ao invés de correr atrás de um virtuosismo e de habilidades específicas que seriam acréscimos técnicos em sua formação, adquiridos por um investimento contínuo em workshops ou outros cursos de formação, consiste em explorar um modo de existência, no qual busca esvaziar o corpo e a mente para tornar-se disponível. (Alice, 2014, p. 38). 
Foi então, no experimento três, intitulado de o que eu não vejo, mas desejo $v^{2} r^{15}$, realizado em fevereiro de 2015, novamente no Parque Farroupilha, que apostamos em arriscar, em nos colocar de forma menos prepositiva e mais propícia aos acasos. Para o filósofo José Gil, para se concretizar um bom encontro, o segredo está nessa abertura, no desejo em realizar algo que só pode acontecer no instante presente, corporificado na relação estabelecida:

O acaso rasga o espaço à volta e dentro do corpo. Quanto mais fortuito for o encontro, mais necessariamente será um bom encontro. Para tanto convém desejar o acaso. Eliminar a razão suficiente e o princípio da casualidade. Dispor-se a acolher o acaso no caos e no microcaos que temos sempre em reserva. Quanto mais espaços vazios nascerem, mais encontros se tornam possíveis, porque maior é a margem do acaso que os acompanha. (Gil, 2013, p. 132).

Desta maneira, perseguimos durante a prática criar e fomentar esses espaços vazios que Gil (2013) explicita acima. E nesta investigação a relação entre o encontro e o acaso de olhos vendados se deu em duas esferas: direta (objetiva) e indireta (sutil). Direta, pois o espaço vazio gerado a partir do não enxergar produziu rapidamente no corpo um leque de possibilidades, diminuindo a racionalidade dicotômica de certo/errado, belo/feio, interessante/desinteressante, deixando-se levar mais instintivamente. Assim, na esfera indireta, sutil, se quebrou algumas barreiras que existem na relação de encontro entre estranhos, como o toque, a confiança, consolidando-se um bom encontro.

Programa de O que eu não vejo, mas desejo ver. Escolher um lugar de passagem de transeuntes no parque. Vendar-me. Andar. Escutar profundamente. Sentir pelos poros. Abrir-me para o inesperado.

Porto Alegre, 08 de fevereiro de 2015

Aos poucos fui descortinando alguns receios, como a desorientação ou o cair. Conforme eu ia me movimentando, lentamente, fui também ganhando confiança

${ }^{15}$ Este artigo é escrito por duas artistas, mas, no experimento três, são narrados experimentos contidos no diário de bordo de Renata Teixeira. Por isso, as partes a seguir estão escritas em primeira pessoa. 
no ato de caminhar, pois fui atingindo cada vez mais consciência do meu corpo e do espaço e do meu corpo neste espaço. À minha volta havia um grupo de senhores tocando samba, ao longe crianças brincando em balanços na pracinha e alguns raios de sol adentravam os galhos das árvores e tocavam a minha pele, eu podia sentir o leve calor. Pessoas passavam por mim falando em baixo tom e raízes atravancavam minha passagem. Nesse percurso não percebi a passagem do tempo, uma forte impressão de alargamento temporal me atravessou, assim como a ampliação do espaço, percebendo minha cinesfera (Laban) sem limites e simultaneamente, em oposição, a força da gravidade parecia agir intensamente, tornando meus movimentos densos, e desta forma, pude identificar novas sensações corporais.

Figura 3 - O que eu não vejo, mas desejo ver, 2015. Foto: Julia Lüdke

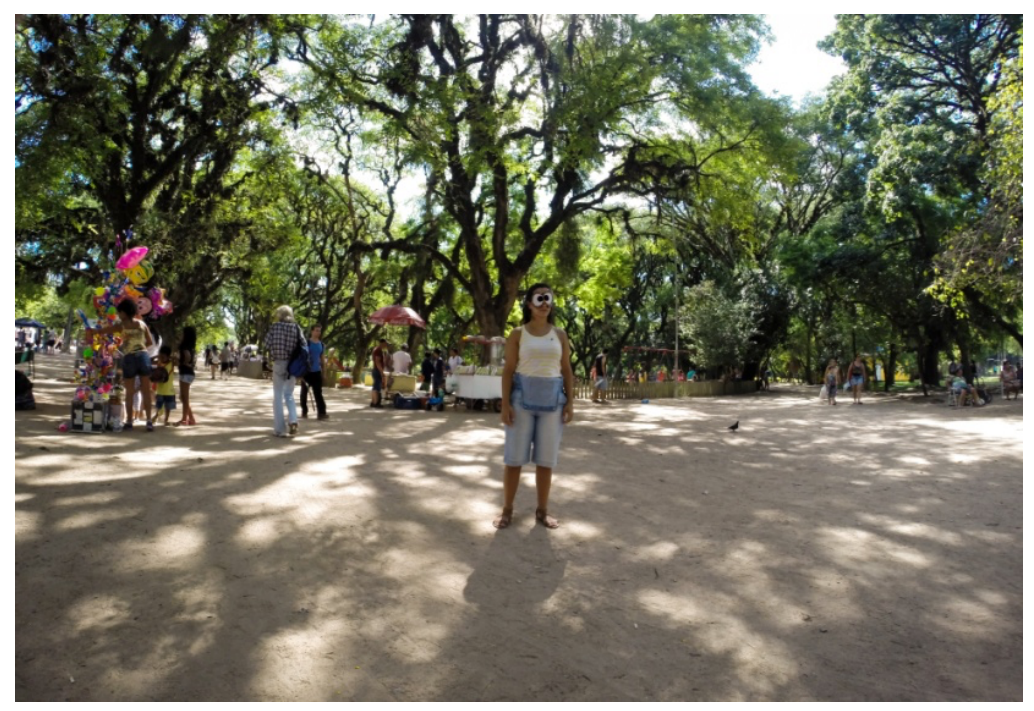

Não havia naquele instante, do ato performativo, nada além do que o tom de voz de quem falava e o toque das mãos de quem me conduzia pelo parque, nada mais do que presença partilhada e afeto. Sendo assim, os julgamentos visuais nesse encontro estavam exclusos para mim, abrindo espaço para uma outra forma de relação com o outro e também para a imaginação, numa transmutação perceptiva através desse estado efêmero criado naquele instante, representado por Caballero (2011, p. 47): 
A emergência de estados efêmeros de encontro que dão espaço a gestos de dissidência e de diferença, e que por isso mesmo invertem as relações com o que nos rodeia, carnavalizando de alguma maneira estas relações, embora num tempo muito breve.

Desta forma, foi através do desenvolvimento desta performance, na fricção entre o impulso e a obstrução, de dentro pra fora, que conseguimos expressar as inquietações deste estudo. Para Dewey "não há expressão sem agitação, sem turbulência" (Dewey, 2010, p. 148), para tanto foi necessário multiplicar as possibilidades de criação e assim, articular, desenvolver, na ação de se fazer e refletir.

\section{Movimento}

Entendemos a prática artística também como forma de circunscrever o conhecimento e a reflexão, e a ação na pesquisa em artes cênicas como potência e motor de pensamento, qualificando a investigação.

Sob esta ótica, ressaltamos nossa condição de artistas, de performers, de mulheres branca, classe média, pois foi através deste ponto de vista não neutro que se desenvolveu a descrição e a análise das práticas. Portanto, identificamos o caráter subjetivo deste estudo e também seus limites, delimitando o interesse em uma Performance do Encontro, dentro de um âmbito tão amplo de $\operatorname{arte}{ }^{16}$, a Arte da Performance (Goldberg, 2006).

A partir de um caráter processual e prático o desenvolvimento da pesquisa foi repleto de descobertas de procedimentos. As experiências de re-enactment, em que a performance de Eleonora Fabião foi rearticulada, recriada e reatualizada através dos experimentos realizados, podem ser compreendidas como memória e transmissão de obras. Este movimento tem sido recorrente na realização de performances, como a artista Marina Abravovic em Seven easy pieces (NY, 2005) em que revive duas de suas obras e refaz as obras de Bruce Nauman, Valie Export,

${ }^{16}$ O recorte não buscou excluir, resumir ou desvalorizar o vasto campo da Performance, ou outras poéticas, como Bodyart, Performance Cultural, Performance Visual, dentre tantas existentes, mas sim procurou investigar, compreender, evidenciar e analisar o encontro como forma de arte e de performance. 
Vito Acconci, Gina Pane e Joseph Beyus, emergindo questões sobre autoria, memória e do "corpo como arquivo vivo." (Lepecki, 2010).

Nesse sentido, entendemos como forma de aprendizado e conhecimento as práticas em performances investidas. Em todas elas, o ir e vir entre teoria e prática impulsionaram e destacaram o encontro, a rua e o afeto na performance como elementos principais e essências para a concepção de uma Performance do Encontro, que se mostrou repleta de ramificações, das quais pretendemos continuar a percorrer e investigar, seguindo esses fluxos de movimento. Assim, concluímos com Dewey, que colabora para pensar esse instante de fechamento de mais um momento dessa trajetória:

Quando se chega a uma conclusão, ela é a de um movimento de antecipação e acumulação, um movimento que finalmente se conclui. A 'conclusão' não é uma coisa distinta e independente; é a consumação de um movimento. (Dewey, 2010, p. 113).

Sendo assim, o encontro estabelecido em uma performance se caracteriza na sua urgência, na sua singularidade, no acontecimento extraordinário, possível naquele momento, daquela maneira e naquele ambiente somente pela arte. Neste sentido, valorizamos iniciativas em performance que disponibilizam espaços para que as pessoas possam compartilhar pensamentos, ideias, experiências e vivenciar a cidade de uma forma mais afetiva. Encontrar-se também como forma de arte, de vida e de transgressão.

Em tempos de COVID19, os exemplos citados parecem utópicos por hora. Propostas simples, aparentemente desprovidas de grandes complexidades, nesse momento podem ser consideradas de grande valor. Enquanto escrevemos esse artigo, e refletimos sobre os exemplos citados, a nostalgia da caminhada a deriva com olhos vendados, sentar para estabelecer um diálogo "converso sobre teatro" e outras performances citadas parecem como algo impossível. Segundo o sociólogo Boaventura, teremos que caminhar rumo às novas possibilidades:

A pandemia e a quarentena estão a revelar que são possíveis alternativas, que as sociedades se adaptam a novos modos de viver quando tal é 
necessário e sentido como correspondendo ao bem comum. Esta situação torna-se propícia a que se pense em alternativas ao modo de viver, de produzir, de consumir e de conviver nestes primeiros anos do século XXI. (Santos, 2020, p.29).

Consequentemente a tais mudanças, artistas rearranjam a cena, tornando a internet a principal ferramenta de divulgação, criação e reunião artística. É por meio do ambiente virtual que a performance tem superado o distanciamento social, deslocando-se para plataformas digitais de diferentes formas, e utilizandose, para além de recursos de registro, de vídeos ou fotos como categorias performáticas.

Portanto, neste momento retornamos ao papel do espectador em um novo espaço, de reconfiguração participativa virtual: online, ao vivo, separada fisicamente, unida virtualmente. Em uma breve relação e análise ${ }^{17}$, face ao que expomos anteriormente sobre as camadas espectatoriais, entendemos a atuação do espectador cibernético em três níveis de interação: o espectador zarpeador, o espectador ouvinte e o espectador solicitado.

O espectador zapeador se utiliza da ação de zapear, que consiste em uma passagem rápida e constante na linha do tempo das redes sociais, em busca de algo interessante, sem se ater de forma demorada em algum conteúdo, estando em trânsito e formando um mosaico de informações. Diferentemente,o espectador ouvinte se prepara para assistir a performance, seja ela online, as famosas lives, ou proposições em vídeo ou imagem, previamente criadas. Ele visualiza o acontecimento, mas de forma ainda distanciada, sem comentários, interferências ou participações significativas. Mantém-se em um quase anonimato, entra, mas fica à espreita, no deleite de testemunha, em um estado audiente.

Já o espectador solicitado é quem assiste a performance nas redes sociais e também é convidado a participar, interagindo e conectando-se, por imagem e ou som, a outros espectadores, por vezes em tempo real, por vezes por meio dos desafios propostos pelos performers. Ele integra o acontecimento performático,

17 O isolamento social no Brasil, decorrente da Covid19, iniciou em março de 2020. Esse isolamento pegou a todos de modo inesperado. O setor de ensino de modo geral e as artes, bem como todos os setores sociais que usam de espaços coletivos fechados, viram-se obrigados a se adaptar a plataformas virtuais. 
cria ações artísticas e mobiliza o ambiente virtual.

É por meio dessas três camadas espectatoriais que estamos transitando nesse período de Pandemia Mundial, em que a adaptação de Boaventura (Santos, 2020) é vista como importante aliada para que emerjam novas possibilidades de expansão territorial da performance, fluindo de uma ação realizada no contexto reservado de nossas casas para um contexto amplificado global.

Quando voltaremos às situações íntimas de troca, de arte e de encontro... os tempos dirão. Enquanto isso, em uma arte que é a do encontro vamos nos adaptando ao desafio das novas tecnologias, buscando conectarmos uns aos outros e criando arte como meio de sobrevivência nesse momento vulnerável e inédito de nossas histórias.

As mulheres performers, Eleonora e Tania, que evocamos nesse artigo, continuam a produzir desdobramentos de encontros performáticos em meio a pandemia como manifestação de persistência e de coragem.

Eleonora está escrevendo um livro e propõe junto com a diretora de teatro Adriana Schneider Alcure o projeto Janela Abertas, que consiste em debater através da plataforma do Facebook uma série de entrevistas com artistas de modo a apoiar a campanha de doações para os hospitais da Universidade Federal do Rio de Janeiro (UFRJ) no combate a COVID-19.

Entre outras ações, Tania Alice promove a prática da yoga do riso, que consiste em "rir, quando não há motivo para se rir". Assim, a yoga do riso foi retomada de forma virtual através das redes sociais, logo nos primeiros dias de quarentena. A artista propôs pelo meio de vídeos Um riso por dia (2020), a fim de fortalecer a saúde física e mental através do humor nesse difícil momento de isolamento em consequência da COVID-19. Além disso, semanalmente, o grupo Performance na Quarentena posta nas redes fotos e vídeos de inúmeros desafios performáticos. Por fim, o cachorro Buda Performer, anima diferentes reenactement tais como imagens da consagrada performance da Marina Abromovich, entre outros desdobramentos. 

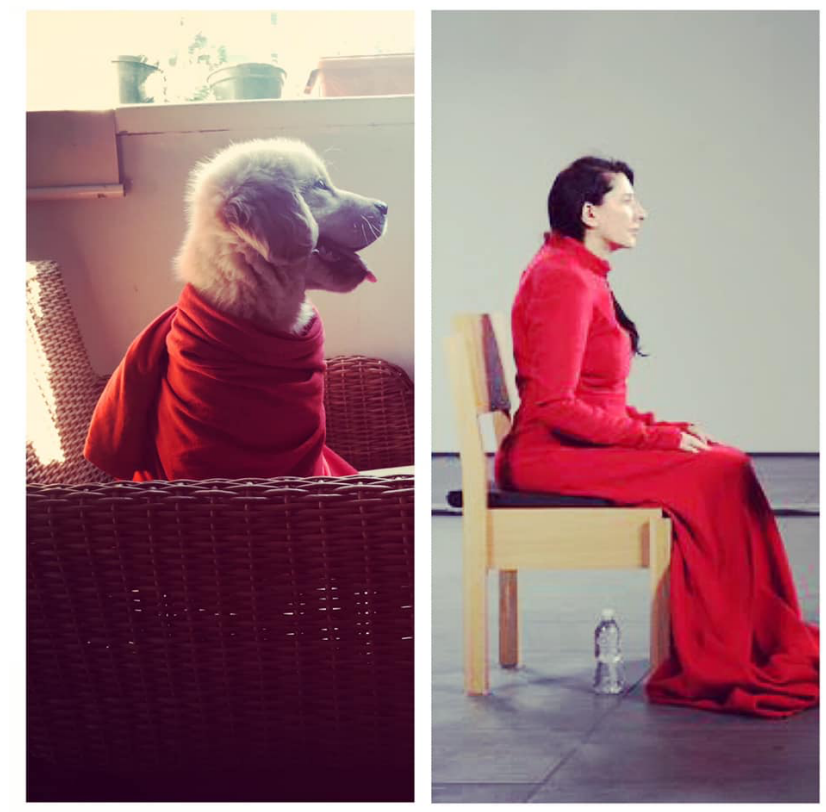

Foto extraida do instagram @buda_performer por Tania Alice, jun.2020

A expectativa de voltarmos a espaços coletivos parece remota, por isso celebramos as ações promovidas por Eleonora e Tania em encontros coletivos virtuais como forma de existir e resistir. Na impossibilidade dos artistas ocuparem a cidade para performances, derivas, espetáculos de modo presencial, os encontros virtuais através de lives, alguns espetáculos em formato online e shows em plataformas virtuais são uma tentativa de artistas e público se reinventarem e estarem juntos.

\section{Referências}

AHMED, Sara. Strange Encounters: embodied Others in Post-Colonialism. London/New York: Routledege, 2000.

ALICE, Tania; REZENDE, Diogo. Performers sem Fronteiras, uma plataforma clínicoperformativa de ações em arte relacional. Revista Fractal, Niterói, v. 29, n. 2, p. 196 202, 2017. Disponível em: http://taniaalice.com/wpcontent/uploads/2013/01/REVISTA-FRACTAL-ARTIGO-PSF-COM-DIGO- 
REZENDE.pdf. Acesso em: 14 mai. 2020.

ALICE, Tania; REZENDE, Diogo; MOTTA, Gilson; VANHAESBROUCK, Karel. Temps obscurs au Brésil - Le retour de la censure. Jornal Mediapart, Paris, 30 nov. 2017. Disponível em: https://blogs.mediapart.fr/taniaalice/blog/301117/temps-obscursau-bresil-le-retour-de-la-censure. Acesso em: 14 mai.2020.

ALICE, Tania; REZENDE, Diogo; MOTTA, Gilson; VANHAESBROUCK, Karel.Jogo da memória Brasil/Nepal. In: 40 Encontro de Pesquisadores dos Programas de PósGraduação em Artes Visuais do Estado do Rio de Janeiro, 2016. Anais Indisciplinas: a arte frente ao urgente, Rio de Janeiro, 2017, p.128-135. Disponível em: https://www.ppgav.eba.ufrj.br/2018/02/12402/. Acesso em: 14 mai. 2020.

ALICE, Tania; REZENDE, Diogo; MOTTA, Gilson; VANHAESBROUCK, Karel. A performance como ( $r$ ) evolução dos afetos. Revista Palco, p.32-43, 2014. Disponível em: http://taniaalice.com/wpcontent/uploads/2012/11/palco2014_Artigo_Tania.pdf. Acesso em: 14 mai. 2020.

ALICE, Tania; REZENDE, Diogo; MOTTA, Gilson; VANHAESBROUCK, Karel. O ReEnactment como Prática Artística e Pedagógica no Brasil. Revista e-misférica, New York, v. 8, 2011.

ALICE, Tania; REZENDE, Diogo; MOTTA, Gilson; VANHAESBROUCK, Karel. A reinvenção do heroísmo na contemporaneidade: a busca de uma estética relacional ativista. Ouviouver, Uberlândia v. 7 n. 2 p. 218-227 jul.|dez. 2011.

BAUMAN, Zygmunt. Modernidade Líquida. Rio de Janeiro: Zahar, 2001.

BELLOTTO, Lisandro Marcos Pires. Um Titere de si mesmo: a imagem como interface dos jogos estabelecidos em uma criação sistêmica. 2013. Dissertação (Mestrado em Artes Cênicas) - Departamento de Arte Dramática, Universidade Federal do Rio Grande do Sul, Porto Alegre, 2013.

BENATONN, Pedro Diniz. DESLOCAMENTO E INVASÃO. Estratégias para a construção de situações de intervenção urbana. 2009. Tese (Doutorado em Teatro)- Centro de Artes, Universidade do Estado de Santa Catarina, Florianópolis, 2009.

BOURDIEU, Pierre. Raisons pratiques. Paris : Éditions du Seuil, 1994, p. 251.

BOURRIAUD, Nicholas. Estética Relacional. São Paulo: Martins Fontes, 2009.

CABALLEIRO, I. D. Cenários limiares: teatralidades, performances e política. Uberlândia: EDUFU, 2011.

COHEN, Renato. Performance como Linguagem: Criação de um Tempo Espaço de Experimentação. São Paulo: Perspectiva, 2002. 
DEWEY, John. Arte como experiência. São Paulo: Martins Fontes, 2010.

FABIÃO, Eleonora. Programa Performativo: O corpo-em-experiência. Revista do Lume, Campinas, n.4, p.1-11, 2013. Disponível em:

https://www.cocen.unicamp.br/revistadigital/index.php/lume/article/view/276/256 Acesso em: 14 mai. 2020.

FABIÃO, Eleonora. Ações Cariocas: 7 Ações para o Rio de Janeiro. Cavalo Louco, Porto Alegre, v. 8, p. 14-18, 2010.

FABIÃO, Eleonora. Definir Performance é um falso problema. Diário do Nordeste, Ceará, 09 jul.,2009. Disponível em:

http://diariodonordeste.verdesmares.com.br/cadernos/caderno-3/definirperformance-e-um-falso-problema-1.281367. Acesso em: 04 dez. 2015.

FABIÃO, Eleonora. Performance e teatro: poéticas e políticas da cena contemporânea. Sala Preta, São Paulo, v.8, p. 235-246, 2008.

FABIÃO, Eleonora. the Energetics of the Paradox: Arthur Bispo Do Rosario's and Lygia Clark's Works in Rio de Janeiro. Tese(Doutorado) - Graduate School of Arts and Science, New York University,2006.

FERNANDES, Ciane. Entre Escrita Performativa e Performance Escritiva: O Local da Pesquisa em Artes Cênicas com Encenação. In: V Congresso ABRACE, 2008. Anais do V Congresso de Pesquisa e Pós-Graduação em Artes Cênicas, Belo Horizonte, p. 1-4. Disponível em:

http://www.portalabrace.org/vcongresso/textos/territorios/Ciane\%20Fernandes\% $\underline{20-}$

\%20Entre\%20Escrita\%20Performativa\%20e\%20Performance\%20Escritiva\%200\%2 OLocal\%20da\%20Pesquisa\%20em\%20Artes\%20Cenicas\%20com\%20Encenacao.p df. Acesso em: 14 abr. 2020.

GIL. José. Um bom encontro? In: SANTO, Cristina E., FABIÃO, Eleonora, SOBRAL, Sonia. Rumos Itaú Cultural Teatro 2010-2012: Encontro. São Paulo: Itaú Cultural, 2013, p.122-133.

GODARD, Hubert. Gesto e percepção. In: SOTER, Silvia e PEREIRA, Roberto. Lições de Dança 3. Rio de Janeiro: UniverCidade, 2001. p.11-35.

GOLDBERG, Roselee. A Arte da Performance. São Paulo: Martins Fontes, 2006.

GURGEL, Alexandra. Pare de se odiar: Porque amar o próprio corpo é um ato revolucionário. Rio de Janeiro: Best Seller, 2018.

HOLLANDA, Heloísa Buarque de. Explosão Feminista: arte, cultura, política e universidade. São Paulo: Companhia das Letras, 2018. 
IPEA. Mulheres ganham 76\% da remuneração dos homens. Disponível em: https://www.ipea.gov.br/portal/index.php?option=com content\&view=article\&id=3 4627. Acesso em: 05 mai. 2020.

LABAN, Rudolf. O Domínio do Movimento. São Paulo: Editora Summus, 1978.

LEPECKI, André. No Metaplano do Encontro. In: SANTO, Cristina E.; FABIÃO, Eleonora; SOBRAL, Sonia. Rumos Itaú Cultural Teatro 2010-2012: Encontro. São Paulo: Itaú Cultural, 2013, p.112-119.

OLIVEIRA, João M.; PINHO, Armando F. O olhar feminista na Performance Artística Autobiográfica. Ex aequo, Lisboa, n. 26, p.57-76,2012. Disponível em: http://www.scielo.mec.pt/pdf/aeq/n27/n27a05.pdf. Acesso em: 14 abr. 2020.

RIBEIRO, Djamila. Lugar de Fala. São Paulo: Pólen, 2019.

RIBEIRO, Djamila. Quem tem medo do feminismo negro? São Paulo: Companhia da LETRAS, 2018.

RIBEIRO, Djamila. Renovar a teoria critica e reinventar a emancipação social. Tradução Mouzar Benedito. São Paulo: Boitempo, 2007.

SANTOS, Boaventura de Souza. A cruel Pedagogia do Vírus. Coimbra: Almedina, 2020.

SILVA, Renata Teixeira Ferreira da Silva. Performance do Encontro: um estudo de práticas performativas. 2016. Dissertação (Mestrado em Artes Cênicas) Departamento de Arte Dramática, Universidade Federal do Rio Grande do Sul, Porto Alegre, 2016.

VENICE INTERNATIONAL PERFORMANCE ART WEEK. Gina Pane. Disponível em: https://veniceperformanceart.org/the-art-week/ritual-body-political-body2014/artists/gina-pane. Acesso em: 13 abr.2020.

WEBER, Suzane da Silva. The Sunday Project. Repertório Teatro \& Dança, v. Ano 13, p. 42-48, 2010.

WEBER, Suzane da Silva. Incorporando a teoria e refletindo a prática em dança contemporânea. V Reunião Científica de Pesquisa e Pós-Graduação em Artes Cênicas. São Paulo, 2009.<<http://www.portalabrace.org/vreuniao/textos/pesquisadanca/Suzi_Weber --_Corpo_social_corpo_dancante.pdf $>>$.

YOUTUBE. Viola Davis. Disponível em:

https://www.youtube.com/watch?v=qcMn2XkunL4. Acesso em: 05 mai. 2020. 
Recebido em: 29/06/2020

Aprovado em: 03/10/2020

Universidade do Estado de Santa Catarina - UDESC

Programa de Pós-Graduação em Teatro - PPGT

Centro de Arte - CEART

Urdimento - Revista de Estudos em Artes Cênicas

urdimento.ceart@udesc.br 